\title{
HOTEL PERFORMANCE: RIGOR AND RELEVANT RESEARCH TOPICS
}

\section{Accepted by IJHM, 2019, 78, 13-26}

Sainaghi, R. Phillips, P. Baggio,R. and Mauri, A.

\begin{abstract}
Academic research (rigor) in alignment with practitioners' challenges (relevancy) has been advocated as a way of overcoming the ivory tower syndrome. Performance measurement is at the heart of strategic management processes, as it provides a mechanism of demonstrating outcomes. Given the importance of this topic for both theory and practice, this article explores the contribution of academic outputs in terms of academic research outputs (rigor) and current practitioners' needs (relevancy).

Using network analysis and cross-citation bibliometric approaches, a sample of 1,155 articles is examined and fourteen clusters are identified. The emergent topics and subtopics from the academic literature are compared to ten insights proposed by Ernst Young to the hotel sector. The findings suggest a good fit between the two approaches together with some gaps. Based from empirical results, nine propositions are articulated.
\end{abstract}

\section{Keywords}

Rigor; relevancy; hotel performance; cross-citation; cluster analysis. 


\section{Introduction}

Performance measurement is at the heart of strategic management and affects the firm's competitive position (Claver-Cortés, Molina-Azorìn \& Pereira-Moliner, 2006). Given the importance of this topic for both theory and practice, this article explores the alignment between academic research outputs (rigor) and, practitioners' needs (relevancy).

In fact, previous reviews focused on performance measurement systems (or simply on hotel performance) are relatively few and all regard the "rigor approach". Sainaghi (2010a) identifies the main research streams contributing to the development of performance measurement together with the different methodological approaches characterizing European, Asiatic and American papers (Sainaghi, 2010b). Sainaghi, Phillips and Corti (2013) use the balanced scorecard framework to analyze trends within the hotel performance literature, by focusing on leading tourism and hospitality journals. With an emphasis on the benefits of strategic planning in hospitality and tourism, Phillips and Moutinho (2014) detected a paucity of research. Pnevmatikoudi and Stavrinoudis (2016) performed a content analysis of 79 articles, distinguishing between studies based on financial and non-financial indicators. A comprehensive review introduces the distinction between three important dimensions of tourism and hospitality literature: unit of analysis (destination, cluster, and firm level), approaches (efficiency, tourism productivity, competitiveness, metrics in use, and performance measurement systems) and disciplines (accounting and financial management, economics and strategy) (Sainaghi, Phillips \& Zavarrone, 2017).

More recently, Altin et al. (2018) provide a critical review based on three dimensions: progress on ontological and espistemological issues; purpose of performance measurement; emerging contexts. The authors suggest that the hospitality and tourism industry has not got any concrete structure. Sainaghi et al (2018a) adopt a bibliometric approach and identify the most cited papers, journals and authors. Furthermore, some trends were analyzed revealing spectacular growth of outputs especially in recent years. Finally, Sainaghi et al. (2018b), using a network analysis, examine salient streams and sub-topic in the hotel performance literature. These works collectively provide evidence of the existence of differing topics within the hotel performance literature, which can be "clustered", to identify different research streams.

On the other hand, some empirical studies mainly conducted by consulting firms suggest that the hospitality industry faces new challenges, such as the development of peer-to-peer platform (e.g. Airbnb phenomenon) that can create a "disruptive innovation" (Lane \& Woodworth, 2016). Hotel brands need to cultivate customer loyalty, drive traffic to their websites and capture a greater share of the wallet. Unfortunately, hotels are structured in silos that make it hard to be flexible in this challenging ecosystem (Deloitte, 2016).

Academics are motivated in part by bibliometrics and rankings, but academic researchers flout their own rules to the effect that their research outputs should be impacting business and society in general as opposed to having academic outputs which include oceans of paper with scant practical relevance. The issue of rigor and relevance is of crucial important for a broader range of stakeholders (Phillips, Moutinho \& Godinho, 2018). Given the paucity of academic endeavours assessing the comparisons between theoretical outputs with practitioner challenges, our particular interest, and focus of this research is to compare hotel performance in terms of rigor and relevance.

The rest of the article explores this gap by asking: How does research outputs align with practitioners' challenges? To address this original research question, we use a recent Ernst and Young (EY) report "Hospitality insights 2016" (EY, 2016) to illustrate a current view of practitioners' challenges. EY research focuses on three core issues which have been enduring and pertinent to the hotel sector for several decades, these being growth (Phillips, 1996), innovation (Phillips, 1999) and culture (Mwaura, Sutton \& Roberts, 1998). We also performed 
a short survey, among hotel managers, to check if they consider EY trustworthy in their business knowledge for hospitality, and how much do they agree with the importance of each of the ten insights of the EY report. The respondents positively confirmed both of these issues. Afterwards, we started the analysis of academic literature through a cluster analysis of outputs (as later presented and discussed), in order to gain fresh insights.

\section{Hotel performance and practitioner challenges}

\subsection{Hotel performance (rigor)}

This section outlines some basic results of the prior performance measurement literature. Two central themes emerge. Firstly, what are the topics analysed? Secondly, what are salient trends observed in these studies?

The basic premise, is that: Hotel performance literature is broad and stratified. As an illustration, the work developed by Sainaghi, Phillips and Zavarrone (2017) consider 978 articles published in the last 20 years, similarly Sainaghi et al. (2018a, 2018b) have used a gross sample of 1,155 papers and a net sample of 734 articles.

The performance measurement literature embraces many different topics. For example, some seminal studies in this field were linked with the four perspectives of the balanced scorecard financial, customer, internal processes, and learning and growth perspectives (Sainaghi, 2010a; 2010b). Sainaghi, Phillips, \& Corti (2013) revealed the multidimensional nature of performance measurement with increasing attention being placed on the customer perspective. Being market oriented in turbulent environments led to the initial growth in customer perspective research, with research on other perspectives in a growth mode. The work of Sainaghi, Phillips and Zavarrone (2017) has shown the stratified structure of performance studies, articulated in five approaches (efficiency, tourism productivity, competitiveness, metrics in use, and performance measurement systems). Competitiveness represents the most attractive approach, while efficiency being the most cited topic. Finally, metrics in use is the most marginal approach and it accounts for the lowest number of citations per paper. Another way to classify the content of performance measurement, is the division between financial and non-financial indicators (Pnevmatikoudi \& Stavrinoudis, 2016). Altin et al. (2018) classified themes distinguishing between: ontological and epistemological issues; purpose; emerging context. The first dimension considers the shift from positivist towards interpretativist; the second from rational control to cultural control and learning; the third from a more static context to a more dynamic one. Finally, Sainaghi et al. (2018b) identified differing clusters within the hospitality and tourism performance measurement literature.

Concerning the second theme, many articles have depicted trends characterizing the nature of the performance measurement literature. A first observation is related to the number of published papers. There is a wide convergence that this research topic is attracting an increasing number of articles, showing a fast growth in the last five years (Sainaghi, Phillips \& Zavarrone, 2017; Sainaghi et al., 2018b). Other trends are related to the specific segmentation proposed by each single review. For example, Pnevmatikoudi and Stavrinoudis (2016) reveal that the majority of analyzed studies measuring hotel performance adopt a narrow view, that is not multidimensional and they tend to focus on a relatively small number of indicators.

\subsection{Practitioner challenges (relevancy)}

We have previously observed the central performance topics, from the academic literature (rigor). Now we will present the emerging gaps for practitioners. 
Table 1. EY insights

\section{EY challenge}

1. Commercial excellence

2. Capital flow from Asia

3. Capital markets

$$
\text { ts }
$$

It focuses on the need to refine growth strategy. Three main questions are posed: i) What drives value for the stakeholders of your business? ii) How does your business react to changing market dynamics? iii) Does your current business plan position you for commercial success? Cross-border capital flows from Asia into global lodging markets are predicted to continue their upward trajectory. The higher property yields and safe investment environments abroad attract investors, such as those in North America, Europe and Australia. This is in contrast to their domestic markets, which have declined due to challenging supply and demand issues. The EY report compares these three different ways to finance the investing activity: equity, debt and emerging alternative financing. In 2016, prominent sources of equity capital and transaction activity will be generated by private equity and cross-border investor groups. Commercial mortgage-backed securities continued to be the largest source of debt for the US hotel sector. Finally, emerging and alternative sources of debt capital such as private equity, hedge funds and even peer-to-peer lending, or structures and higher loan-to-value ratio loans. It refers to the increasing percentage of world population based in urban areas. Unprecedented

4. Creative demand for both residential and commercial real estate developments have further raised the development already high barriers to entry in urban environments. As a result, hotel developers are employing creative and sophisticated techniques to maximize return in both established and emerging development markets.

The focus here is on the relevance of cultural variables in managing this activity. In fact, the

5. Merger integration combination of two companies with different corporate strategies and infrastructures requires the integration not only of data and systems, but also a merger of cultures and purposes. The EY report suggests that $85 \%$ of failed acquisitions are attributable to the mismanagement of cultural issues.

The relationships between hospitality firms and destinations play a pivotal role (Baggio \& Sainaghi, 2011, 2016; Sainaghi \& Baggio, 2017). “Critical success factors for tourism markets" centers on the

6. Critical success increasing relevance of the destination area in order to define and emphasize a destination's factors competitive attributes (d'Angella, De Carlo \& Sainaghi, 2010; Sainaghi, 2006), to communicate the destination's purpose to customers in key feeder markets and to ensure customer experiences align with the destination's purpose across various tourism products.

It is operationalized in three promising areas: i) loyalty programs (moving from rigid to more

7. Technology and innovation personalized programs), ii) revenue management (re-thinking the forecasting approach, integrating new data dispersed around the firms, and delivering unexpected benefits to targeted customers) and iii) internet of things (exploring a network of everyday physical objects that contains electronics, sensors, and exchanges data).

"Gaming" refers mainly to casino hotels and the progressive changing customer demographics 8. Global gaming between older clients and Millennials, which show very different gaming and entertainment preferences. In fact, these young players are seeking an interactive, social gaming experience where they can use their skills to exert control over outcomes.

This trend is indicative of the increasing importance played by lodging platforms (e.g. Expedia, TripAdvisor and Airbnb). In this new competitive area, three relevant questions emerge: i) How is

9. Sharing peer-to-peer inventory affecting my hotel's performance and value? ii) Is my hotel adequately economy protected against the growing supply of peer-to-peer inventory? iii) How do I consider peer-topeer inventory to better understand its potential impact on the feasibility for new lodging developments?

\section{Revenue} recognition The evolving environment requires continuing innovation in the criteria underlying the revenue recognition standard issued by both the Financial Accounting Standards Board (FASB) and the International Accounting Standards Board (IASB).

Source: Adapted from EY (2016).

The first key question is related to the information source capable of identifying the practitioner challenges in the hospitality industry. Our attention was, first, on the many specialized consulting firms, variously involved in this sector, such as Smith Travel Research, PFK, CBRE. 
However, none of them has published an in-depth report describing the emerging challenges. In fact, we have not considered as report, simple interviews that trace some future trends (i.e. STR, 2018). For this reason the research team used the EY document (later described) consisting of ten trends relevant for the hospitality industry.

Despite not specializing in hospitality, EY is an authoritative actor in the field of strategic consulting. Furthermore, academic researchers make use of EY documents. In fact, researching in Scopus "EY" in published papers and reviews since 1996 to present, the research team has identified more than 124 thousand works citing this consulting company. More than 7 thousand refer to "social science", "business, management and accouting" or "economics and finance". With ten challenges identified, these will be sufficient to provide a comprehensive platform to help deliver a rich source of fresh knowledge. Table 1 succinctly presents each EY challenge.

\section{Methodology}

As previously stated, this study performs a cross-citation analysis within the broad stream of "hotel and performance". To develop the study, some central themes are relevant: i) the sample selection, ii) the time horizon, iii) the cross-citation analysis and iv) the network and cluster analysis.

\subsection{Sample selection}

Articles were selected according to three criteria - as suggested in some previous reviews focused on hotel performance (e.g. Sainaghi, 2010a, 2010b; Sainaghi, Phillips \& Corti, 2013) or more generally to other hospitality research streams (Chan \& Hsu, 2016; Sourouklis \& Tsagdis, 2013; Tsai, Pan \& Lee, 2011; Tsang \& Hsu, 2011) -: i) keywords, ii) journals, and iii) year of publication. Concerning the first point (keywords), given the focus on hotel performance, these two words were used as keywords, in accordance to previous studies.

Concerning the second point (journals), some previous reviews explicitly focus their attention only on tourism or hospitality sector (e.g. Jang \& Park, 2011; Lucas \& Deery, 2004; Li, 2008). However, some recent works, such as Sainaghi, Phillips and Zavarrone's (2017) study, clearly demonstrate the relevance of non-tourism and non-hospitality journals. The empirical study was carried out at the beginning of August 2016 and two keywords ("hotels and performance") were researched in abstract, title and keywords in the Scopus database. Only journals published in English were included in the sample. Concerning the time horizon, the analysis embraces 20 years, from 1996 to 2015. The timeframe was partly determined by the Scopus dataset, which was incomplete prior to 1996, as confirmed in previous studies (Benckendorff \& Zehrer, 2013). These choices assure a wide coverage of the literature. Using these three criteria together, the sample includes 1,155 papers. The research team verified the match with hotel performance stream by analyzing all the papers. Only articles that explore determinants of results or, on the other hand, propose performance measurement systems are included in the final sample. 268 papers are excluded (23\%), because, despite using the keywords, they did not really address hotel performance issues. It is interesting to note that $90 \%$ of these outliers (241) are "disconnected papers", which means such papers have not received any cross-citations. Therefore, the proposed methodology (cross-citation) helps researchers to verify the relevance of used keywords.

Table 2 reports the sample size. Net sample counts 734 papers. Based on this basket of articles, a cluster analysis was realized, as depicted in the next paragraph (§3.2). 
Table 2. Sample size

\begin{tabular}{|c|c|c|c|c|c|c|}
\hline \multirow[b]{2}{*}{ Papers } & \multicolumn{2}{|c|}{ Gross sample } & \multicolumn{2}{|c|}{ Outliers } & \multicolumn{2}{|c|}{ Net sample } \\
\hline & \# & $\%$ & \# & $\%$ & $\#$ & $\%$ \\
\hline Gross sample & 1,155 & $100 \%$ & 268 & $23 \%$ & 887 & $77 \%$ \\
\hline Disconnected papers & 394 & $34 \%$ & 241 & $90 \%$ & 153 & $17 \%$ \\
\hline Connected papers & 761 & $66 \%$ & 27 & $10 \%$ & 734 & $83 \%$ \\
\hline
\end{tabular}

\subsection{The time horizon}

This section introduces and discuss a methodological, problem related to the different time horizons of practice and rigor. In fact, while the EY report identifies ten insights for the hotel industry in 2016, the rigor literature embraces twenty years (1996-2015). A question to consider is whether there is a time mismatch? Figure 1 shows that in reality, alignment consists of two elements - cross sectional and longitudinal. In fact, for answering the ten emerging questions (cross sectionally) in a given point of time it is important to consider (longitudinal) the previous research flow. Clearly, as the academic publication process will frequently exceed a one year time period, detailed gap analysis year by year is problematic. Furthermore, given the wide array of academic research, as the sample size confirms, some papers can anticipate future trends that will impact pratictioners (practice). An example can help to illuminate this point. One trend of the EY report is related to the so-called peer-to-peer platforms (as Airbnb) and their impact on tourism and hospitality industry. This problem is formalized by EY researchers in 2016 but in the academic literature there are many papers published before the emergence of this insight. For example, there is a seminal research stream in the consumer behavior area of inquiry (i.e. Belk, 2007; Felson \& Spaeth, 1978) with some articles in the tourism and hospitality field previously published (Dredge \& Gyimóthy, 2015; Guttentag, 2015; Molz, 2013; Pizam, 2014). The goal of this paper is not to verify the overlapping between rigor and relevancy in the same period of time, but showing how academic research outputs can contribute to the challenge highlighted by EY.

Figure 1. The time horizon of the analysis between rigor and relevancy

$$
\begin{aligned}
& \text { EY (2016) report } \\
& \text { with } 10 \text { insights }
\end{aligned}
$$

20 years of academic research (1995-2015). Are

there some connections to the EY insights?

\subsection{Cross-citation analysis}

We propose a cluster analysis based on network analysis, where nodes are papers and links are cross-citations (as described later in the methodology section). Citations are objective measures, which illustrate the exchange of ideas in a field of enquiry. Collectively, citations are influential as they represent quality at journal and at individual level. Citation relationships among authors can be categorized in three key ways: co-citation, coupling and cross-citation 
(Wang, Qiu \& Yu, 2012). Co-citation analysis uses pairs of documents, which often appear together in reference lists and have something in common (Benckendorff \& Zehrer, 2013; Xiao $\&$ Smith, 2008). Two articles are bibliographically coupled if their reference list share one or more of the same cited documents (Yuan, Gretzel \& Tseng, 2015). Two papers must cite the same source to be coupled, whereas co-citation relies on any papers listed in another's reference list. The coupling strengthens as the number of citations they share increase.

Cross-citation analysis assesses the relationships among journals, articles and/or authors to identify patterns (Howey et al., 1999). Given the focus of the present study on communities (clusters) cross-citation appears the most useful approach. It helps researchers to identify groups of papers that share relationships, and groups of articles that are disconnected. As illustrated in previous papers, this relational approach is mainly based on network analysis (Benckendorff \& Zehrer, 2013; Figueroa-Domecq et al., 2015; Gomezelj, 2016; Hu \& Racherla, 2008; Köseoglu, Sehitoglu, \& Craft, 2015; Racherla \& Hu, 2010; van der Zee \& Vanneste, 2015; Ye, Li \& Law, 2013; Yuan, Tseng \& Chang, 2014).

\subsection{Network and cluster analysis}

Citation network analysis has been used several times and proven to be an effective tool to analyze the structure of scientific research. This method enables the illustration of different domains that can uncover emerging research strands in many disciplines, with tourism included (Cardillo et al., 2006).

For the analysis we built a network with papers selected as nodes and the cross-citations that a paper makes to other papers as links. A traditional clustering technique would require the collection of a number of characteristics of the papers examined. Then the application of some methods to organize the papers into clusters based on the statistical similarity of the different variables (Baggio \& Klobas, 2017; Baggio \& Sainaghi, 2011; 2016; Sainaghi \& Baggio, 2017). A network approach, instead, works on the possibility of recognizing the internal structure of the network by identifying groups of nodes (papers) that are more densely connected between themselves than to other nodes in the network (modules, clusters or communities). Several algorithms exist that differentiate themselves in terms of the network characteristics they consider (directionality, weights etc.) and resolution power (Fortunato, 2010).

Here we use the so-called Louvain method proposed by Blondel et al. (2008) which is a heuristic algorithm that optimizes a modularity metric Q, designed to measure the strength of the division of a network into different modules. $Q$ is the fraction of the edges that fall within the given groups minus the expected fraction if edges were distributed at random. The higher the value of $\mathrm{Q}$, the more defined and separated the modules are. By tuning a resolution parameter, the Louvain method enables the observation of communities at different scales. Here we use a value of 1 that gives a moderate resolution power thus allowing detecting reasonably sized and separated clusters.

Based on our net sample (734 papers), our calculations identifiedfound 14 clusters with a modularity index $\mathrm{Q}=0.65$, that implies a well-clustered network. Successively, each community was further analyzed with the same algorithm, thus highlighting groups of similar papers within the different clusters. A closer (qualitative) inspection of these groups allowed new topics to emerge.

Figure 2 reports the whole network (left-side) and, as an example, the four broadest clusters $(11,12,13$ and 14) are represented, putting in evidence some sub-clusters (as later presented). 
Figure 2. The papers' network and the main clusters.

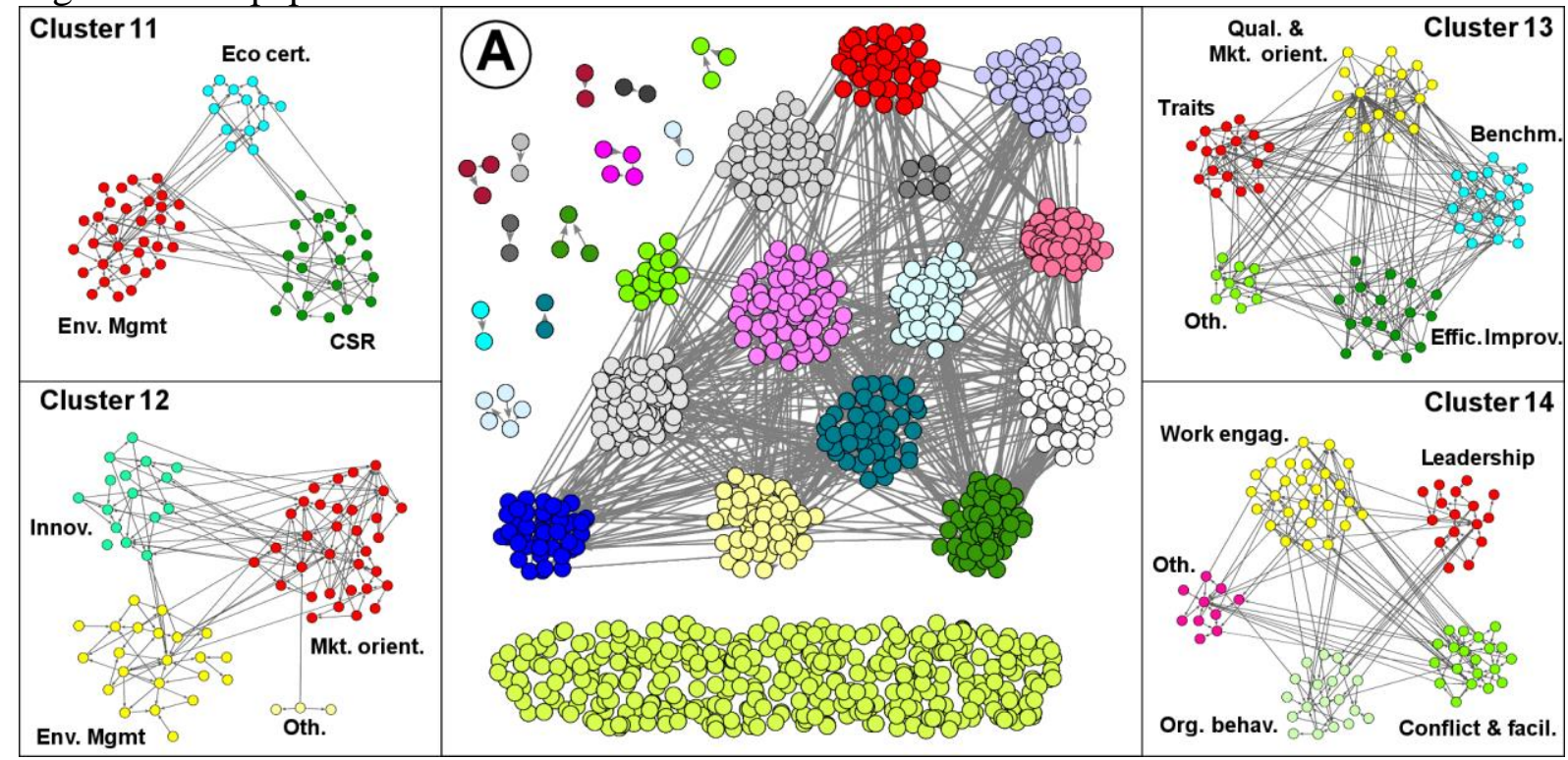

Legend: The central panel A contains the whole network, with all the clusters uncovered. As an example a closer view of the four largest clusters $(11,12,13$ and 14) is shown with their different components (see text for details).

\section{Rigor and relevance}

This paragraph compares the trends emerging from the literature (rigor) with those proposed in the EY study (relevancy). The analysis is structured at the following levels: first, a short qualitative description of each cluster is reported ( $\$ 4.1)$; second, a holistic approach is developed, connecting the ten insights with the 14 clusters $(\$ 4.2)$; third, the two more relevant connections (weighted in term of papers) are analytically investigated, in order to understand what kind of suggestions emerge from rigor in order to deal with the EY insights. These two relevant connections are represented by commercial excellence $(\$ 4.3)$ and merger integration (§4.4).

\subsection{A short qualitative presentation of the 14 clusters}

This paragraph presents a brief summary of the fourteen identified clusters. A full description is reported in a separate paper (Sainaghi, et al 2018b). The first cluster includes six papers focused on Human Resource Management (HRM), not published in top journals and mainly based on qualitative methodology, such as case study. The topics explored are mainly related to job motivation and satisfaction. The topic of Cluster 2 is termed external determinants of hotel performance and the independent variables are mainly represented by macroeconomic antecedents. In terms of discipline, this cluster is related to finance. Three main topics are identified: i) monetary policy or other macro-economic variables, such as consumer confidence, ii) business cycle and corporate governance, and iii) crisis and external shocks. Cluster 3 consists of 40 papers. The basic topic of this cluster is internal operational and soft determinants of hotel performance. The dependent variable is mainly represented by business performance, which is a broad concept usually including both operational and financial measures. Independent variables belong to five different groups: i) performance measurement systems, ii) information technology, iii) relational capabilities, iv) intellectual capital and v) competitive strategy.

Cluster 4 includes 41 papers. The cluster deals with market and product diversification, on one side, together with some processes linked to diversification: i) performance measurement systems, using some typical hospitality indices (sales measures) and financial indices (risk and 
stock return), ii) diversification strategy, iii) HRM, iv) organizational competencies, and v) technology. Despite the fact Cluster 5 includes 44 papers, it appears homogeneous both in terms of dependent and independent variables. Dependent variables are mainly represented by business performance, operational performance and process performance, using indicators relating to HRM, such as job performance. The independent variables are principally related to: i) HRM practices (the largest group, that accounts for more than 50\%), ii) agglomeration and geographical competition, plus some and iii) other marginal themes, such as service quality and corporate governance.

The Cluster 6 accounts for 45 papers. The predominant topic is strongly related to competitive strategy with four sub-groups: i) competitive strategy (the largest group), ii) sales performance determinants, iii) outsourcing strategy, and iv) strategic practices and benchmarking. The underlying discipline is management and in particular strategic management. The Cluster 7 consists of 55 papers; the general topic being performance indicators or performance measurement systems. Three main sub-groups were identified: i) non-accounting measures, ii) BSC approach, and iii) accounting indices. The main discipline of this cluster is accounting.

Cluster 8 includes 56 papers; the topic of this cluster is social media and comprises four subgroups: i) social media and online reviews, ii) websites, iii) market orientation, and iv) environmental management. The dependent variable is usually represented by operational performance. The discipline of this cluster is marketing.

With 59 papers, the central theme of Cluster 9 is brand management and three sub-groups were identified: i) brand management, ii) pricing, and iii) marketing strategies and crisis management. Given the focus on selling processes, unsurprisingly the dependent variables are mainly related to "operational performance", usually represented by ADR, occupancy and RevPAR, or customer satisfaction. The prominent discipline is marketing.

Cluster 10 includes 62 papers and develops two interrelated topics: i) customer satisfaction and ii) service quality. These two sub-groups are interrelated, since the ability of service quality of improving customer satisfaction. Marketing is the main discipline. This basket of papers usually use customer satisfaction as a dependent variable; financial and competitive measures are more rarely used.

Cluster 11 includes 68 papers with focus on i) environmental management (EM), ii) corporate social responsibility and iii) eco-certification. Unsurprisingly, the Journal of Sustainable Tourism is the second most popular journal in terms of the number of published papers. The underlying topic is represented by "sustainability", which can be broken down into environmental or eco-sustainability, on one side, and social or stakeholder sustainability, on the other.

Cluster 12 accounts for 74 papers primarily related to: i) market orientation, ii) environmental management, and iii) innovation, plus some other marginal themes. The underlying discipline is marketing.

Cluster 13 is the second largest group with 80 papers and reveals a strong focus on efficiency, measured mainly using DEA models. Four sub-groups were identified: i) efficiency improvement, ii) benchmarking, iii) quality and market orientation, and iv) hotel traits. The underlying feature is efficiency, sometimes integrated with marketing and management.

Cluster 14 is the largest group with 91 papers. The topic of this cluster is job satisfaction, usually operationalized as a dependent variable, while antecedents are related to four sub-groups: i) work engagement, ii) organizational citizenship behaviour (OCB), iii) conflict and facilitation, and iv) leadership, empowerment and knowledge sharing. The discipline of this cluster is HRM.

\subsection{Holistic approach}

Based on cluster analysis, as reported in the methodology section, 14 clusters and some subtopics were identified. Table 3 reports the overlapping between insights and clusters. 
Table 3. Rigor and relevance.

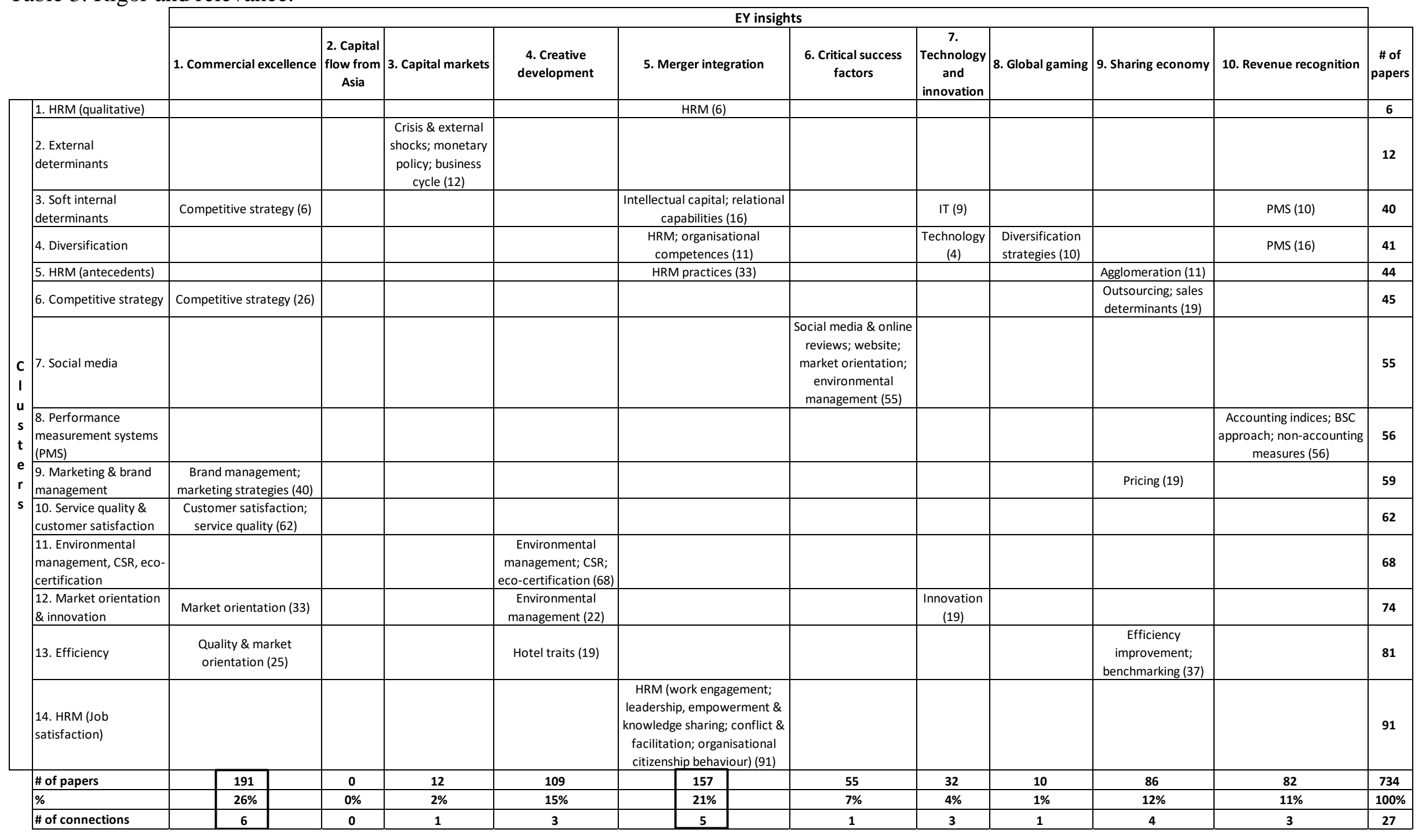


Before considering the results, some premises are given. There is some common overlap between rigor and practice: the 14 clusters cover 9 (of ten) insights. The only one relevant insight omitted is "capital flow from Asia". A second consideration suggests the presence of some clusters that have a clear link with one and only one EY insight, while others show relationships with morea single insights. The broad scope of some issues has made it difficult to find a precise location. An example will help to clarify this point. The third cluster (soft internal determinants) shows four sub-topics: competitive strategy; intellectual capital and relational capabilities; information technology (IT); performance measurement systems. For some sub-topics there are potentially more connections with EY insights: for instance, the competitive strategy can create commercial excellence, but also creative development, or can be a source of critical success factors or innovation. The relationships depicted in Table 3 propose only one link, focusing on the most relevant connection between a specific sub-topic and a precise EY insight, as it emerges after reading the articles.

Finally, the penultimate line shows three different intensities between rigor and practice. Two insights (commercial excellence, 26\%; merger integration, 21\%) account $47 \%$ of the sample; three insights show values higher than 10\%, representing 37\% (creative development, 14\%; sharing economy $11 \%$; revenue recognition, $11 \%$ ), while the four remaining EY topics (capital markets, 2\%; critical success factors, 7\%; technology and innovation, 4\%; global gaming, 2\%) attract only $15 \%$. For this reason, in the next sub-paragraphs only the first two very "strong" relationships (squared in Table 3) are analyzed and discussed.

\subsection{Commercial excellence}

At the heart of strategic management is the concept of competitive advantage, which translates to higher levels of firm performance (Phillips \& Mouthinho, 2014; Sainaghi, Phillips \& d'Angella, 2018). For hospitality firms, the competitive advantage is variously related to the destination context (d'Angella, De Carlo, Sainaghi, 2010; Sainaghi, 2006) and it is influence by special events (Sainaghi \& Mauri, 2018; Sainaghi et al. 2018c; Sainaghi, Mauri \& d'Angella, 2018). So, the first column of Table 3 being commercial excellence aligns rigor with practitioner relevance, and in particular point to a clear path to accelerate growth. This insight is structured around three aspects: understanding what drives value; taking an agile approach to the market; developing a strategic business model, as suggested by the EY report. Six connections are identified and this column accounts for the highest percentage (26\%, Table 3 ). Just the two strongest relationships are analyzed: marketing and brand management (cluster 9); service quality and customer satisfaction (cluster 10). The emerging topics from rigor are particular insightful to identify what drives value (brand equity and internal business), how to take an agile approach to the market (managing customer satisfaction) and how developing a strategic business model (centered on both brand and service quality management).

\section{Marketing and brand management}

Focusing on the first topic, Figure 3 summarizes the main evidence emerging from rigor. Brand management appears as a central topic and is operationalized by considering brand equity and internal branding. This first issue is particular important to identify both what drives value and how to develop a strategic business model.

External brands are often described as a name, term, design, logo, symbol, identity, or trademark that are developed and designed to identify the goods or services offered by one entity and further differentiate the entity from its competitors (Kim \& Kim, 2005). Many studies note the tremendous investment necessary to position a new brand, the long time required and the low probability of success (Jackson \& Qu, 2008). By contrast, brand equity generates value to both clients, shareholders and other stakeholders. From the consumer point of view, key 
benefits include the reduction of perceived risks and search costs, while owners can charge a price premium, increase market share, or reduce marketing costs (Kayaman \& Arasli, 2007). Having clarified the concept of brand, branding is usually described as organizational processes geared towards creating perceived value beyond the tangible goods or services offered by the enterprise (Xu \& Chan, 2010).

Brand equity is mainly operationalized along four variables: brand awareness (or brand associations); brand image; perceived quality; brand loyalty. These determinants are employed in many studies usually with positive relationships with hotel performance. Prior studies propose some hierarchal relationships among these components. For example, $\mathrm{Xu}$ and Chan (2010) suggest that brand awareness, brand associations, and quality of experience are determinants of brand loyalty. Kayaman and Arasli (2007) found that perceived quality influence brand loyalty and brand image on one side, and brand loyalty influences brand image, on the other. While Kim and Kim (2005) revealed a stronger effect generated by brand awareness and perceived quality on firm performance, compared to brand image and loyalty. These relationships are reported inside the block of brand equity in Figure 3 and demonstrate that research has not reached a state of maturity. Fresh enquries are necessary to fully understand and appreciate the precise relationhips depicted in Figure 3.

Figure 3. Brand management: evidences from rigor

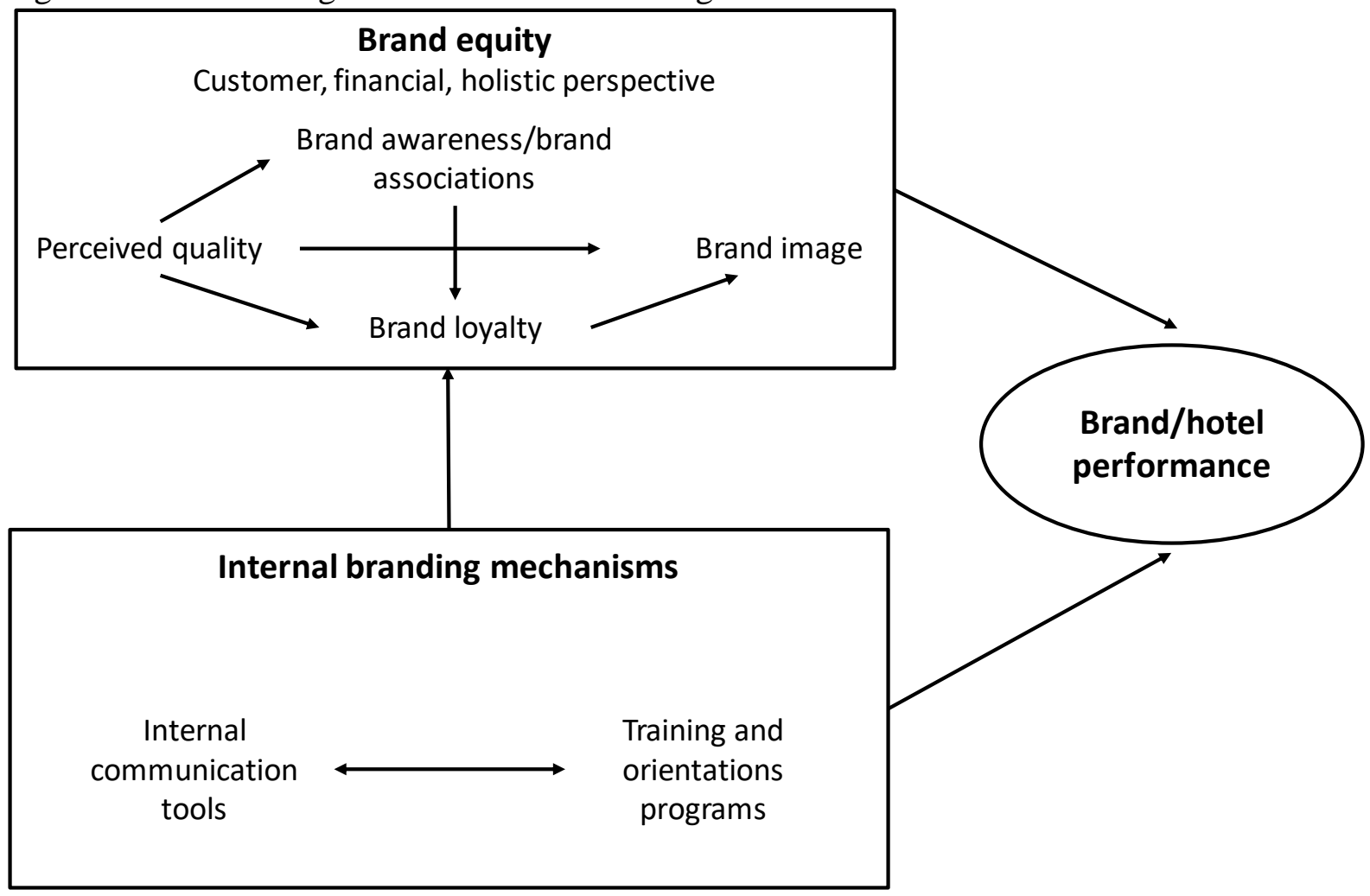

Legend: rectangles = independent variables; circle = dependent variable; arrows = relationships

Control variables and moderators play a crucial role in measuring the effects of brand equity on performance. For example, O'Neill, Mattila and Xiao (2006) point out that brands affect the market value of mid-price and upscale hotels beyond the usual contribution attributed to net operating income and revenue per available room (RevPAR). Alternatively, Hanson et al. (2009) found performance improvements for hotels that rebranded within a higher market segment. O'Neill and Carlbäck (2011) found that branded hotels have higher levels of occupancy than unaffiliated. However, unbranded hotels outperform in term of rates and 
RevPAR. Hotels that merely changed brands without also changing their scale reported no significant variation in financial results (Hanson et al., 2009). These obeservations illustrate the fickle nature of the hotel management business in terms of performance metric. Also, the type of hotel matters too. In terms of the bottomline drivers, high levels of occupancy may be benefical, but RevPar is ultimately more important. So, some of the findings of prior studies suggests a need for further investigation.

The second driver of Figure 3 is represented by internal branding, which considers promoting the brand within an organization with its employees as the key audience (Punjaisri, Wilson \& Evanschitzky, 2009). Internal branding is therefore defined as a nurturing process whereby employees are provided with brand knowledge. Such a process enables employees to understand the meaning of a corporate brand and pass on a consistent brand experience to customers (Tsai, Cheung \& Lo, 2010). This is vital when the experience provided by employees is a key differentiator. In the hospitality industry, employees are both internal resources and part of the product. Hence, employee quality is an important factor, and employees should be the primary marketing targets of managers (King, 2010).

In Figure 3, two main drivers of internal branding are identified: on one-side internal communication tools (group meeting, briefing, notice boards, newsletters, and logbooks) and, on the other, training and orientation tools (orientation, development course, and training). Internal branding can have a direct and indirect effect on performance. Phillips and Moutinho (2014) observation are pertinent, as they note the critical nature of strategic planning praxis which considers and asks what are the key activities of formulating and implementing strategic plans. These can include workshops, use of analytic and creative tools.

\section{Service quality and customer satisfaction}

This second theme is particularly relevant to answer EY questions about taking an agile approach to the market and developing a strategic business model. Concerning the first point, customer satisfaction is a focal issue, while service quality is a key ingredient for developing a strategic business model.

As depicted in Figure 4, the relationship with hotel performance is articulated in two steps: some analytical determinants (left side) are able to impact on service quality or customer satisfaction and these latter are related to hotel performance (variously operationalized). Furthermore, service quality influences customer satisfaction (down arrow). The determinants are mainly related to internal (or supply) items, with some interests in external antecedents. This latter area includes overall value for money and online reviews (Mauri \& Minazzi, 2013; Phillips et al., 2015). But matters are now more complicated as a customer even if satisfied, may not engage in repeat business. 
SUPPLY/INTERNAL PERSPECTIVE

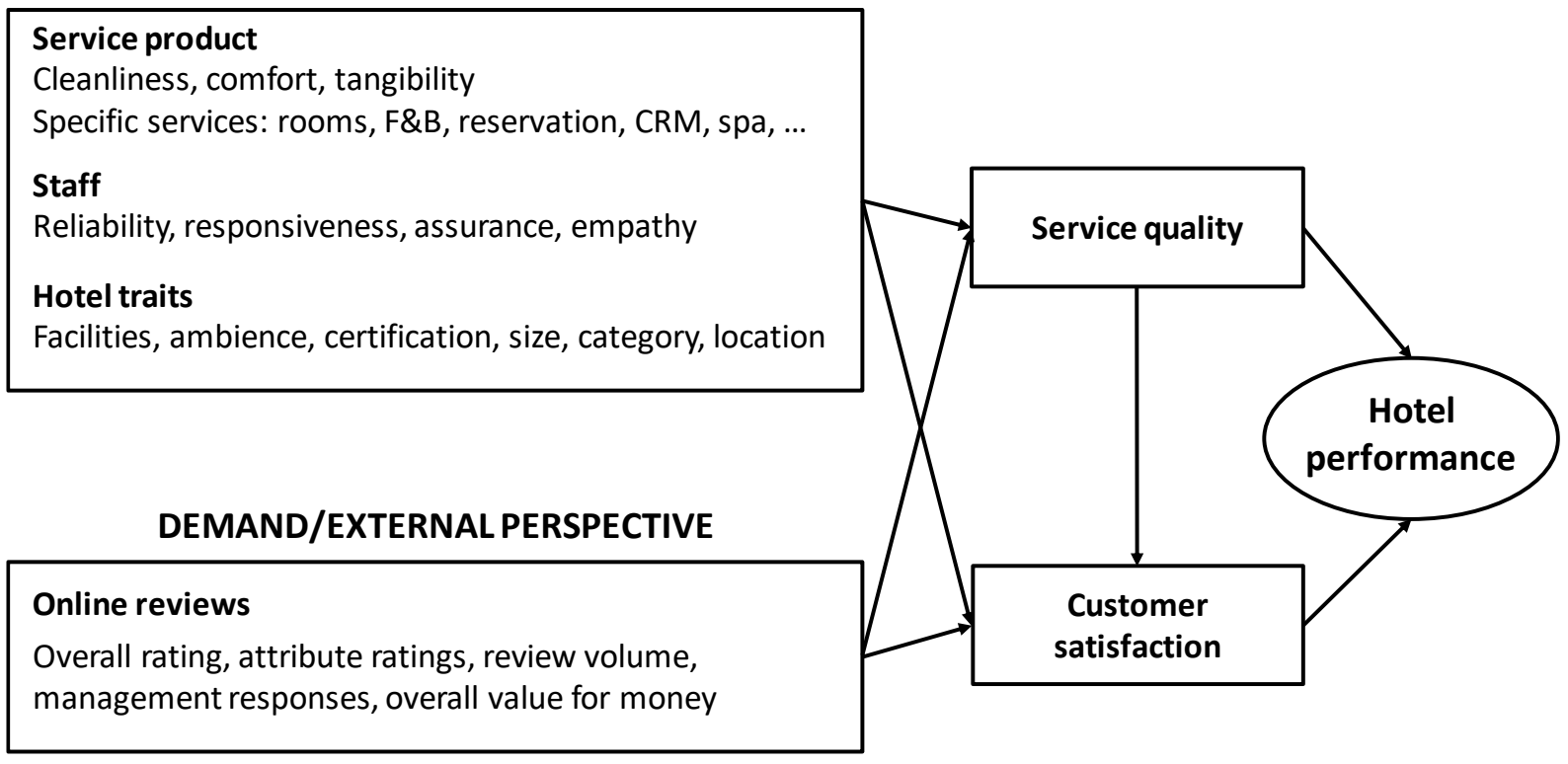

Legend: rectangles = independent variables; circle = dependent variable; arrows = relationships

Focusing on supply determinants, three main blocks are used by researchers: service product, staff and hotel traits (Albayrak, 2015). The supply perspective is the most developed in the literature and within them, the service product is analyzed in many contributes. Some studies measure the quality of single services, as cleanliness, comfort or tangibility, while others focus on specific services, such as rooms (Chaves, Gomes \& Pedron, 2012), F\&B (Giritlioglu, Jones \& Avcikurt, 2014), reservation systems (Ali, 2015), CRM (Garrido-Moreno, Lockett \& GarcíaMorales, 2014). The items reported in Figure 4 represent some examples, in fact some papers propose many other antecedents or categories (as ancillary and core services). Staff is used in some studies as a determinant of both service quality and customer satisfaction. This variable is primarily operationalized by considering reliability (the ability to deliver a service coherently with the hotel standards), responsiveness (the ability to provide prompt and quick service or to provide the extra level of service to handle customer special requests), assurance (experience in the field, courtesy and respect for clients), and empathy (personal initiative, ability to understand specific customer needs, and individual attention to clients). These four determinants are related to the work of Parasuraman and the SERVQUAL system to measure service quality. Parasuraman, Zeithaml and Berry (1985) identified ten dimensions in assessing service quality reduced to five in some papers (Mauri, Minazzi \& Muccio, 2013). The fifth variable is represented by tangibility, positioned in service product block in Figure 4. In fact, this dimension considers the physical part of the hospitality product (parking areas, building exteriors, dining area, food) (Tsai \& Lin, 2014). The SERVQUAL approach (reduced to five dimensions) is used in some papers (as Serrat, 2011).

The last block is represented by hotel traits and includes an array of variables mainly related to the building, as the category, location, size (number of rooms), and number of facilities. Some papers explore the presence of certification and in particular eco-certification. Findings suggest that certified hotels usually account for lower levels of performance, giving the extra cost generated by the additional controls (Heras-Saizarbitoria, Arana \& Boiral, 2015). 
In the case of merger of two companies what is most critical is not embodied by data and systems integration, but culture and people. As reported in the EY study, 85\% of failed acquisitions are attributable to the mismanagement of cultural issues. For this reason, we suggest an important link between this insight and HRM, with a particular focus on cultural aspects, as later clarified. Table 3 depicts five connections between clusters $(1,3,4,5,14)$ and merger integration. It is clear that the focus is not solely represented by merger integration, but more generally the relevance of HRM and cultural variables in hospitality organizations. The issues emerging from rigor are reported in Figure 5 and are centered on the following topics: intellectual capital and relational capabilities; work engagement; leadership, empowerment and knowledge sharing; role stress; organizational citizenship behavior. Each of these points will be discussed, by explaining the link with "culture and people", according to EY insight. Given the high number of clusters (and therefore papers) involved in this insight, we place emphasis only on some relevant themes and focus more on recent contributes.

161

Figure 5. Culture and people

Intellectual capital (IC) and relational capabilities (RC)

IC: human, structural and relational capital

RC: social capital, stakeholder theory (trust and commitment)

\section{Work engagement}

Mediator: family support, hope, challenge stressors, work-family conflict, ... Antecedents: role clarity, supervisory support, peer support, org. resources

Leadership, empowerment, knowledge sharing (KS)

Servant, empowering, spiritual leadership, behavioral integrity

KS: Learning orientation and knowledge collecting. Antecedents of KS:

organizational and individual factors; organizational learning

Stress role

Role ambiguity, role conflict, role overload; customer-related social

stressors; work-family relationships

organizational citizenship behaviour

Antecedents: workload, emotional intelligence, emotional labour, servant leadership

Legend: rectangle = independent variables; circle = dependent variable; arrows = relationships

Intellectual capital and relational capabilities are rooted in the resource-based view and knowledge-based view of the firm (Barney, 1986). Basically, this theoretical stream assumes that firms own different types of resources which enable them to develop different strategies (Wernerfelt, 1984). Resources that are valuable, rare, inimitable and non-substitutable are able to create sustainable competitive advantage (Amit \& Schoemaker, 1993). In this perspective, intellectual capital is a set of contemporary value drivers that productively transform resources into material assets with added value (Bontis, Janošević \& Dženopoljac, 2015). Zeglat and Zigan (2013) explore three components of intellectual capital, represented - in analogy to social capital (Sainaghi \& Baggio, 2014) - by human, structural and relational capital (also defined in some papers as customer capital). Human capital is the knowledge that employees take with them when they go home after work. Examples of human capital are innovation capacity, knowhow, experience, team effort, ande employee flexibility. Structural capital is the knowledge that remains in the company after employees go home after work. It consists of organizational routines, procedures, systems, corporate culture, databases and so forth. Relational capital entails relationships with external stakeholders (clients, suppliers and partners). Empirical 
papers find a positive relationship between intellectual capital and business performance, operationalized both considering financial (ROA, gross operating profit) and operating (RevPAR) performance (Sainaghi, 2011).

Relational capabilities (Sainaghi \& De Carlo, 2016) present some analogies with relational capital (Campopiano, Minola, \& Sainaghi, 2016) and they are rooted in two different research streams: social capital and stakeholder theory. Nahapiet and Ghoshal (1998) define social capital as the sum of the actual and potential resources embedded within, available through, and derived from the network of relationships possessed by an individual or social unit. Similarly, stakeholder theory states that the long-term survival and success of a firm is determined by its ability to establish and maintain relationships with its critical stakeholders. In these perspectives, relational capabilities are able to create trust and commitment with stakeholders (Lo, 2013) and, more generally, to develop a customer relationship management (CRM) approach (Mohammed, Rashid \& Tahir, 2014).

With reference to EY insights, the firm's ability to develop intellectual capital and relational capabilities help hotels enhance their success in managing their culture. In the case of mergers, these abilities help in developing integrating processes. But the challenge of the 1980s and 1990s are different from today. The digitization of businesses necessitates the identification of new ways to develop and manage intellectual and relational capabilities. The main driver is the reality that hotels need to elucidate how the relationhips between intellectual capital and innovation can be successfully deployed within a dynamic environment.

Work engagement is usually defined by citing Schaufeli et al. (2002): "positive, fulfilling, workrelated state of mind that is characterized by vigor, dedication, and absorption" (p. 72). Employees who feel energetic, are enthusiastic and are immersed in their work. They have desirable job outcomes such as reduced turnover intentions, quality performance in the workplace, and higher levels of job and career satisfaction (Karatepe, 2014). It has been shown that employees who are actively disengaged in their work seem to result in $\$ 450$ to $\$ 550$ billions of lost productivity per year in the United States (Karatepe, 2015).

Studies focusing on work engagement are mainly centered on the work of Karatepe. Generally speaking, many contributes use work engagement as a mediator role in measuring job performance, in combination with other HRM variables, such as organizational resources, family support, "hope" (defined as positively oriented human resource strengths and psychological capacities), challenge stressors (composed by work overload and job responsibility), and work-family conflict (Karatepe et al., 2014). The dependent variable is usually operationalized in term of job performance, customer service, and turnover intentions. The link between work engagement and the firm culture is evident. In fact, without work engagement it is difficult to create a clear firm identity. Furthermore, work engagement has some positive spin-offs on service quality and customer satisfaction (as analyzed in the previous paragraph).

Leadership, empowerment and knowledge sharing is a relevant sub-topic. Leadership and empowerment are able to improve customer service quality and employee's membership as well as to implement knowledge sharing approaches. The relevance of empowerment is related to the increasing number of employees with a high degree of autonomy. In this context, hotel supervisors with empowering behavior may encourage employees to improve their service attitude and passion for customers. Wu and Chen (2015) find that empowering leadership is an antecedent of the psychological contract, where the latter is defined as individual beliefs, shaped by the organization, regarding terms of an exchange agreement between individuals and their organization (Rousseau, 2004). Empowering leadership affects team creativity (Hon \& Chan, 2012), while organizational empowerment influences job satisfaction, affective commitment 
and psychological empowerment (Kazlauskaite, Buciuniene \& Turauskas, 2011). Similarly, (2010) propose the "leadership competency", while Kwak and Kim (2015) suggest the ability of servant leadership to influence organizational citizenship behavior. In their study, servant leaders refer to a leadership style by the use of which the leader facilitates the development of followers to achieve their potential by building self-confidence, performing as a role model, developing trust, and providing valuable support and resources. Guchait, Simons and Pasamehmetoglu (2016) proposed the ability of behavioral integrity to influence service recovery performance, which refers to frontline employees' abilities and actions to resolve a service failure. Concerning the EY insight, the message emerging from these contributes is clear, in the field of hospitality organizations a new leadership paradigm needs to replace traditional forms of leadership.

Knowledge-sharing behavior is important in the hospitality industry due to the immense costs of knowledge loss caused by high rates of employee turnover (Kim \& Lee, 2013). However, employees often refuse to share knowledge because they worry that doing so may reduce their opportunities for promotion or because doing so requires uncompensated time and energy (Bock et al., 2005). Kim and Lee (2012) explore antecedents of knowledge sharing and find positive relationships with organizational factors (facilitating conditions and social factors) and some individual variables (enjoyment in helping others, knowledge self-efficacy, extrinsic motivators, anticipated usefulness, and reciprocal relationships). Aizpurúa, Saldaña, and Saldaña (2011) identify another determinant of knowledge sharing: organizational learning. This last concept is defined as the process of improving actions through better knowledge and understanding. With reference to the EY insight, the ability to design a learning organization is a central point to improve knowledge sharing mechanisms.

Job stress can be defined as stress that employees experience in the workplace environment (Karatepe \& Karatepe, 2009). Job stress influences employees' performance at work, which also affects the customers' perceptions of service quality and customer satisfaction (Karatepe \& Tizabi, 2011). Job stress is influenced by several factors, called role stress that is both a source and an important premise of job stress. The work of Akgunduz (2015) examines three role stressors: role conflict, role ambiguity and role overload. The first two variables are negatively related to job satisfaction, while role overload shows a positive link. Akgunduz focuses on internal processes, and Karatepe and Nkendong (2014) explore the mediating role of emotional exhaustion in the relationships between customer-related social stressors and job performance. Another relevant role stressor is represented by work-family relationships. Given the hotel industry's long and irregular working hours, high levels of job insecurity, and high work stress, some studies posit that hotel frontline employees are prime candidates for role conflict between work and family (Zhao, Mattila \& Ngan, 2014). This work-family conflict refers to the incompatible and competing time and emotional demands from work and family (Karatepe \& Kilic, 2007). This sub-topic provides a clear insight concerning "culture and people": hotels should control role stress in order to avoid an excessive level of stress that generates turnover intentions, on one side, and culture disruption, on the other.

Finally, organizational citizenship behavior is usually self-initiated by employees. Although this kind of behavior can enhance the overall effectiveness of organizational functions, the formal organizational reward system does not recognize behavior. Similarly, Kwak and Kim (2015) define organizational citizenship behavior as extra role behaviors that are not formally required and rewarded by the organization's systems, but enhance organizational functioning and effectiveness. Organizational citizenship behavior is a relevant topic for hospitality firms, given the relevance of employee-customer relationship. Papers have identified some 
antecedents of organizational citizenship behavior, including workload (Wei, Qu \& Ma, 2012),

\section{Discussion and conclusions}

Conclusions are articulated at two levels (as findings): firstly, some propositions are drawn based on the connections between the ten EY insights and the 14 clusters ( $\$ 5.1)$; secondly, some remarks are made based on the analytical inspection of commercial excellence and merger integration (§5.2). Finally, some limitations and future research agenda are reported (§5.3).

\subsection{Holistic approach}

From an academic perspective, there is a need to take stock of outputs and ascertain its relevance with practice. We are not asserting that we have performed a gap analysis by matching outputs with current industry themes. This would have been rather difficult for several reasons. First, the time it takes to get from a kernel of an idea to the idea appearing in a topranked academic journal paper can two years. Six months to perform the research and write the paper and another twelve to eighteen months for the review process and revise and resubmit resubmissions. Then it can take several years for the ideas of the research to permeate to practice. The business world places a premium on knowledge, as a source of competitive advantage (Starkey \& Madan, 2001). If we as academics ignore this issue, our research may lead to irrelevant theory and flawed practice. Our findings identify several areas associated with practice associated with impact and the preparedness of researchers in helping to achieve national development objectives around future growth strategies, such as the UK government's Industrial Strategy (Great Britain. Department for Business, 2017).

At the first level, the analysis reported in the Table 3 allows us to identify some topics developed in literature (rigor) and able to operationalize the ten EY insights (relevancy), which can help growth, innovation and dealing with culture. A first important remark concerns the multidisciplinary approach that emerges from Table 3. Researchers have analyzed the EY insights using different theoretical approach: strategy, accounting, finance, efficiency, marketing, stakeholder theory, HRM, environmental management, technology, and agglomeration theory. This breadth of approaches indicates the complexity characterizing the lodging industry and the need of a unitary and holistic approach.

Proposition 1. To address EY insights, hotel management should work collaboratively with academics, so that bespoke holistic and interdisciplinary approaches can evolve. Academics should strive to create a synthesis between different research streams and share knowledge.

Table 3 proposes answers for each insight, ranging from 1 to 6 (see last line). In total, 27 subtopics are proposed to operationalize nine connected insights, with an average of 3 sub-issues. Based on these findings, the following proposition is stated.

Proposition 2. To operationalize each connected insight, many sub-topics are relevant, showing the multi-dimensionality of each challenge. 
Focusing the attention on a single insight, HRM is the discipline that accounts for the highest number of sub-topics, showing the importance of people and the complexity of organizational skills (intellectual capital, relational capabilities); organizational variables (organizational commitment, organizational competences, organizational citizenship behavior, leadership, empowerment and knowledge sharing); as well as the ability to manage conflicts.

Proposition 3. HRM is the discipline that accounts for the highest number of sub-topics.

Taken together the nine connected insights, marketing (inclusive of social media and online reviews) is the discipline linked with the highest number of EY challenges. In fact, marketing is related to commercial excellence (brand management, marketing strategies, customer satisfaction, service quality, market orientation, and quality \& market orientation), critical success factors (social media \& online reviews, website, and market orientation), and sharing economies (sales determinants, and pricing). Based on this evidence, the following proposition is formulated.

Proposition 4. Marketing sub-topics play a pivotal role in the EY insights.

Finally, six trends are related to more than two clusters - commercial excellence is linked to six clusters, merger integration with five, sharing economy with four, creative development; technology and innovation; revenue recognition with three - while the three remaining insights focused only on one cluster (capital markets; critical success factors; global gaming). This evidence supports the following proposition.

Proposition 5. EY insights are mainly complex trends, connected with more than two clusters, which demonstrates the need for more impactful research together with an interdisciplinary approach.

\subsection{Analytical inspection}

The second level of conclusions focuses on the two analytical inspections developed in $\$ 4.2$ (business excellence) and $\$ 4.3$ (merger integration).

Concerning business excellence, four different sub-topics were analyzed: brand equity, internal branding, and service quality and customer satisfaction. As previously discussed, brand equity refers primarily to customer-based perspective and branding is centered on four determinants: brand awareness (or brand associations); brand image; perceived quality; brand loyalty. Despite the fact that branding is widely considered a key issue for hospitality firms, there is still a discussion regarding the juxtaposition between hotels affiliated with branded hotel chains, on one side, and independent hotels, on the other. Furthermore, the subject becomes more complex too because it involves strategies of either hotel properties, franchisors and management companies (Xiao, O'Neill, \& Mattila, 2012). Some studies, as the work of Carvell, Canina and Sturman (2016), have found no advantages in all segments for either the affiliated hotels or the comparable unaffiliated properties. By contrast, the paper of O'Neill and Carlbäck (2011) affirms that branded hotels achieve higher occupancy but lower rates. Based on these opposing evidences, the following proposition is stated:

Proposition 6. Concerning business excellence, there is a contradicting relationship between affiliated and unaffiliated hotels and their operating performance (occupancy, ADR and RevPAR).

Employees in the hospitality industry are both an internal resource and part of the product. For this reason, internal branding plays a crucial role. In particular, this nurturing process whereby employees are dialoged and trained with brand knowledge, influences brand equity. 
Proposition 7. Internal branding plays a crucial role in creating and communicating the hotel

Finally, considering the binomial service quality and customer satisfaction, the first variable influences the second one and both are positively related to hotel performance (as depicted previously in Figure 4). Service quality can be analyzed and operationalized in many views. The current literature shows a prevalent supply approach mainly focused on service product. Proposition 8. Service quality influences customer satisfaction; both are positively related to hotel performance.

Focusing on merger integration, prior work has identified five determinants: intellectual capital and relational capabilities; work engagement; leadership, empowerment, knowledge sharing; stress role; organizational citizenship behavior. This broad list suggests the complexity in order to work on "culture and people" in the hospitality industry.

Proposition 9. In order to create and maintain a positive integrative culture, the rigor analysis suggests the relevance of many internal organizational processes.

We now summarize the propositions formulated in Section 5.1 and 5.2 in Table 4.

Table 4. The formulated propositions

\section{Holistic approach}

Proposition 1. To address EY insights, hotel management should work collaboratively with academics, so that bespoke holistic and interdisciplinary approaches can evolve. Academics should strive to create a synthesis between different research streams and share knowledge.

Proposition 2. To operationalize each connected insight, many sub-topics are relevant, showing the multi-dimensionality of each challenge.

Proposition 3. Focusing on one single insight, HRM is the discipline that accounts for the highest number of sub-topics.

\subsection{Limitations and further research}

\section{Analytical inspection}

Proposition 4. Marketing sub-topics play a pivotal role in the EY insights.

Proposition 5. EY insights are mainly complex trends, connected with more than two clusters, which demonstrates the need for more impactful research together with an interdisciplinary approach.

Proposition 6. Concerning business excellence, there is a contradicting relationship between affiliated and unaffiliated hotels and their operating performance (occupancy, ADR and RevPAR).

Proposition 7. Internal branding plays a crucial role in creating and communicating the hotel brand. Internal branding positively affects brand equity.

Proposition 8. Service quality influences customer satisfaction; both are positively related to hotel performance. Proposition 9. In order to create and maintain a positive integrative culture, the rigor analysis suggests the relevance of many internal organizational processes.

This paper uses the SCOPUS database, which despite being authoritative will result in some research outputs not being accessible because of their unavailability at the time of the research. The SCOPUS database is not exhaustive of all the possible publications relating to tourism performance measurement, and we do not include books in our sample.

Groups of papers (cluster and main sub-groups) were identified using cluster analysis, while the corresponding topics (and sub-topics) were defined by reading each article. This method, assures reliability (cluster analysis) but, on the other hand, reduces generalizability, given the subjectively of content analysis. Some recent reviews (Sainaghi, Phillips \& Zavarrone, 2017) 
411 propose an objective method, based on keywords and computer-aided text analysis (CATA). 412 Future researchers can deploy this technique to compare results achieved using the two 413 approaches.

414 The clusters were identified using a software approach. This method, on one side, assures reliability but, on the other, some papers can fit within more than one cluster. This limitation is well known in the literature, however cluster analysis is considered a good tool to reduce the complexity of large sample. This is illustrated in the case of the present study, which is based on 734 papers. Furthermore, network analysis has proved to provide outcomes that often are 419 not simply (or at all) visible using other methods.

420 Some limitations are applicable to the method used to operationalize practitioner challenges 421 (relevancy). The use of EY report on its own, cannot fully represent the needs of the entire hotel sector. In fact, it is difficult to rely on a single consulting firm, which is not focused on the lodging sector. Future studies can pursue new ways to operationalize relevancy, by including interviews with key players or by considering more consulting reports. The EY insights may reflect relevant topic for practitioners but not for researchers. Said differencly, academic research does not have to concern itself with all of industry challenges. But the UK government expects academics to make impacts beyond their traditional networks. In this study the research team has compared the EY insights of 2016 with academic papers published in the previous 20 years. We could have created a match between the EY report of 431 2016 and academic research published for the previous two decades. 


\section{REFERENCES}

Aizpurúa, L. I., Saldaña, P. E., \& Saldaña, A. Z. (2011). Learning for sharing: an empirical analysis of organizational learning and knowledge sharing. International Entrepreneurship and Management Journal, 7(4), 509-518.

Akgunduz, Y. (2015). The influence of self-esteem and role stress on job performance in hotel businesses. International Journal of Contemporary Hospitality Management, 27(6), 1082-1099.

Albayrak, T. (2015). Importance Performance Competitor Analysis (IPCA): A study of hospitality companies. International Journal of Hospitality Management, 48, 135-142.

Ali, F. (2015). Service quality as a determinant of customer satisfaction and resulting behavioural intentions: A SEM approach towards Malaysian resort hotels. Turizam: znanstveno-stručni časopis, 63(1), 37-51.

Altin, M., Koseoglu, M. A., Yu, X., \& Riasi, A. (2018). Performance measurement and management research in the hospitality and tourism industry. International Journal of Contemporary Hospitality Management, 30(2), 1172-1189.

Amit, R., \& Schoemaker, P. J. (1993). Strategic assets and organizational rent. Strategic Management Journal, 14(1), 33-46.

Asree, S., Zain, M., \& Razalli, M. R. (2010). Influence of leadership competency and organizational culture on responsiveness and performance of firms. International Journal of Contemporary Hospitality Management, 22(4), 500-516.

Baggio, R., \& Klobas, J. (2017). Quantitative Methods in Tourism: A Handbook (II ed.). Bristol, UK: Channel View.

Baggio, R., \& Sainaghi, R. (2011). Complex and chaotic tourism systems: towards a quantitative approach. International Journal of Contemporary Hospitality Management, 23(6), 840-861.

Baggio, R., \& Sainaghi, R. (2016). Mapping time series into networks as a tool to assess the complex dynamics of tourism systems. Tourism Management, 54, 23-33.

Barney, J. B. (1986). Strategic factor markets: Expectations, luck, and business strategy. Management Science, 32(10), 1231-1241.

Belk, R. (2007). Why not share rather than own? The Annals of the American Academy of Political and Social Science, 611(1), 126-140.

Benckendorff, P., \& Zehrer, A. (2013). A network analysis of tourism research. Annals of Tourism Research, 43, 121-149.

Blondel, V. D., Guillaume, J. L., Lambiotte, R., \& Lefebvre, E. (2008). Fast unfolding of communities in large networks. Journal of Statistical Mechanics, P10008.

Bock, G. W., Zmud, R. W., Kim, Y. G., \& Lee, J. N. (2005). Behavioral intention formation in knowledge sharing: Examining the roles of extrinsic motivators, social-psychological forces, and organizational climate. MIS quarterly, 29(1), 87-111.

Bontis, N., Janošević, S., \& Dženopoljac, V. (2015). Intellectual capital in Serbia's hotel industry. International Journal of Contemporary Hospitality Management, 27(6), 13651384.

Campopiano, G., Minola, T., \& Sainaghi, R. (2016). Students Climbing the Entrepreneurial Ladder: Family Social Capital and Environment-related Motives in Hospitality and Tourism. International Journal of Contemporary Hospitality Management, 28(6), 1115-1136.

Cardillo, A., Scellato, S., \& Latora, V. (2006). A topological analysis of scientific coauthorship networks. Physica A, 372, 333-339.

Carvell, S. A., Canina, L., \& Sturman, M. C. (2016). A comparison of the performance of brandaffiliated and unaffiliated hotel properties. Cornell Hospitality Quarterly, 57(2), 193201. 
Chan, E. S., \& Hsu, C. H. (2016). Environmental management research in hospitality. International Journal of Contemporary Hospitality Management, 28(5), 886-923.

Chaves, M. S., Gomes, R., \& Pedron, C. (2012). Analysing reviews in the Web 2.0: Small and medium hotels in Portugal. Tourism Management, 33(5), 1286-1287.

Chiang, C. F., \& Hsieh, T. S. (2012). The impacts of perceived organizational support and psychological empowerment on job performance: The mediating effects of organizational citizenship behavior. International Journal of Hospitality Management, 31(1), 180-190.

Claver-Cortés, E., Molina-Azorìn, J. F., \& Pereira-Moliner, J. (2006). Strategic groups in the hospitality industry: intergroup and intragroup performance differences in Alicante, Spain. Tourism Management, 27(6), 1101-1116.

d'Angella, F., De Carlo, M., \& Sainaghi, R. (2010). Archetypes of destination governance: a comparison of international destinations. Tourism Review, 65(4), 61-73.

Deloitte. (2016). The hotel of the Future. https://www2.deloitte.com/content/dam/Deloitte/us/Documents/consumerbusiness/us-cb-the-hotel-of-the-future.pdf.

Dredge, D., \& Gyimóthy, S. (2015). The collaborative economy and tourism: Critical perspectives, questionable claims and silenced voices. Tourism Recreation Research, 40(3), 286-302.

EY. (2016). Global hospitality insights: top 10 thoughts for 2016. http://www.ey.com/gl/en/industries/real-estate/ey-global-hospitality-insights-2016.

Felson, M., \& Spaeth, J. L. (1978). Community structure and collaborative consumption: A routine activity approach. American Behavioral Scientist, 21(4), 614-624.

Figueroa-Domecq, C., Pritchard, A., Segovia-Pérez, M., Morgan, N., \& Villacé-Molinero, T. (2015). Tourism gender research: A critical accounting. Annals of Tourism Research, 52, 87-103.

Fortunato, S. (2010). Community detection in graphs. Physics Reports, 486(3-5), 75-174.

Garrido-Moreno, A., Lockett, N., \& García-Morales, V. (2014). Paving the way for CRM success: The mediating role of knowledge management and organizational commitment. Information \& Management, 51(8), 1031-1042.

Giritlioglu, I., Jones, E., \& Avcikurt, C. (2014). Measuring food and beverage service quality in spa hotels: A case study in Balıkesir, Turkey. International Journal of Contemporary Hospitality Management, 26(2), 183-204.

Gomezelj, D. O. (2016). A systematic review of research on innovation in hospitality and tourism. International Journal of Contemporary Hospitality Management, 28(3), 516558.

Great Britain. Department for Business, E. a. (2017). Building our industrial strategy: green paper.

Guchait, P., Simons, T., \& Pasamehmetoglu, A. (2016). Error recovery performance: the impact of leader behavioral integrity and job satisfaction. Cornell Hospitality Quarterly, 57(2), 150-161.

Guttentag, D. (2015). Airbnb: disruptive innovation and the rise of an informal tourism accommodation sector. Current issues in Tourism, 18(12), 1192-1217.

Hanson, B., Mattila, A. S., O'Neill, J. W., \& Kim, Y. (2009). Hotel rebranding and rescaling effects on financial performance. Cornell Hospitality Quarterly, 50(3), 360-370.

Heras-Saizarbitoria, I., Arana, G., \& Boiral, O. (2015). Do ISO 9001-certified hotels get a higher customer rating than non-certified ones? International Journal of Hospitality Management, 51, 138-146. 
Hon, A. H., \& Chan, W. W. (2012). Team creative performance: The roles of empowering leadership, creative-related motivation, and task interdependence. Cornell Hospitality Quarterly, 54(2), 199-210.

Howey, R. M., Savage, K. S., Verbeeten, M. J., \& Van Hoof, H. B. (1999). Tourism and hospitality research journals: Cross-citations among research communities. Tourism Management, 20(1), 133-139.

$\mathrm{Hu}, \mathrm{C} .$, \& Racherla, P. (2008). Visual representation of knowledge networks: A social network analysis of hospitality research domain. International Journal of Hospitality Management, 27(2), 302-312.

Jackson, L. A., \& Qu, H. (2008). A Conceptual Framework for Managing Lodging Brands: A Balanced-Scorecard Approach. Journal of Quality Assurance in Hospitality \& Tourism, 9(2), 108-134.

Jang, S., \& Park, K. (2011). Hospitality finance research during recent two decades: subjects, methodologies, and citations. International Journal of Contemporary Hospitality Management, 23(4), 479-497.

Karatepe, O. M. (2014). Hope, work engagement, and organizationally valued performance outcomes: an empirical study in the hotel industry. Journal of Hospitality Marketing \& Management, 23(6), 678-698.

Karatepe, O. M. (2015). The effects of family support and work engagement on organizationally valued job outcomes. Turizam: znanstveno-stručni časopis, 63(4), 447464.

Karatepe, O. M., \& Karatepe, T. (2009). Role stress, emotional exhaustion, and turnover intentions: does organizational tenure in hotels matter? Journal of Human Resources in Hospitality \& Tourism, 9(1), 1-16.

Karatepe, O. M., \& Kilic, H. (2007). Relationships of supervisor support and conflicts in the work-family interface with the selected job outcomes of frontline employees. Tourism management, 28(1), 238-252.

Karatepe, O. M., \& Nkendong, R. A. (2014). The relationship between customer-related social stressors and job outcomes: the mediating role of emotional exhaustion. Ekonomska istraživanja, 27(1), 414-426.

Karatepe, O. M., \& Tizabi, L. Z. (2011). Work-related depression in the hotel industry: a study in the United Arab Emirates. International Journal of Contemporary Hospitality Management, 23(5), 608-623.

Karatepe, O. M., Beirami, E., Bouzari, M., \& Safavi, H. P. (2014). Does work engagement mediate the effects of challenge stressors on job outcomes? Evidence from the hotel industry. International Journal of Hospitality Management, 36, 14-22.

Kayaman, R., \& Arasli, H. (2007). Customer based brand equity: evidence from the hotel industry. Managing Service Quality: An International Journal, 17(1), 92-109.

Kazlauskaite, R., Buciuniene, I., \& Turauskas, L. (2011). Organisational and psychological empowerment in the HRM-performance linkage. Employee Relations, 34(2), 138-158.

Kim, H. B., \& Kim, W. G. (2005). The relationship between brand equity and firms' performance in luxury hotels and chain restaurants. Tourism management, 26(4), 549560.

Kim, T. T., \& Lee, G. (2013). Hospitality employee knowledge-sharing behaviors in the relationship between goal orientations and service innovative behavior. International Journal of Hospitality Management, 34, 324-337.

Kim, T., \& Lee, G. (2012). A modified and extended Triandis model for the enablers-processoutcomes relationship in hotel employees' knowledge sharing. The service industries journal, 32(13), 2059-2090. 
King, C. (2010). "One size doesn't fit all” Tourism and hospitality employees' response to internal brand management. International Journal of Contemporary Hospitality Management, 22(4), 517-534.

Köseoglu, M. A., Sehitoglu, Y., \& Craft, J. (2015). Academic foundations of hospitality management research with an emerging country focus: A citation and co-citation analysis. International Journal of Hospitality Management, 45, 130-144.

Kwak, W. J., \& Kim, H. K. (2015). Servant leadership and customer service quality at Korean hotels: Multilevel organizational citizenship behavior as a mediator. Social Behavior and Personality: an international journal, 43(8), 1287-1298.

Lane, J., \& Woodworth, R. M. (2016). The sharing economy checks in: An analysis of Airbnb in the US. CBRE Hotels' Americas Research.

Li, L. (2008). A review of entrepreneurship research published in the hospitality and tourism management journals. Tourism Management, 29(5), 1013-1022.

Lo, Y. H. (2013). Stakeholder management in the Chinese hotel industry: the antecedents and impacts. International Journal of Contemporary Hospitality Management, 25(4), 470490.

Lucas, R., \& Deery, M. (2004). Significant developments and emerging issues in human resource management. International Journal of Hospitality Management, 23(5), 459472.

Mauri, A. G., \& Minazzi, R. (2013). Web reviews influence on expectations and purchasing intentions of hotel potential customers. International Journal of Hospitality Management, 34, 99-107.

Mauri, A. G., Minazzi, R., \& Muccio, S. (2013). A review of literature on the gaps model on service quality: a 3-decades period: 1985-2013. International Business Research, 6(12), 134-144.

Mohammed, A. A., Rashid, B. B., \& Tahir, S. B. (2014). Customer relationship management (CRM) Technology and organization performance: is marketing capability a missing link? an empirical study in the malaysian hotel industry. Asian Social Science, 10(9), 197-212.

Molz, J. G. (2013). Social networking technologies and the moral economy of alternative tourism: The case of couchsurfing. org. Annals of tourism research, 43, 210-230.

Mwaura, G., Sutton, J., \& Roberts, D. (1998). Corporate and national culture-an irreconcilable dilemma for the hospitality manager? International Journal of Contemporary Hospitality Management, 10(6), 212-220.

Nahapiet, J., \& Ghoshal, S. (1998). Social capital, intellectual capital, and the organizational advantage. Academy of Management Review, 23(2), 242-266.

O’Neill, J. W., \& Carlbäck, M. (2011). Do brands matter? A comparison of branded and independent hotels' performance during a full economic cycle. International Journal of Hospitality Management, 30(3), 515-521.

O'Neill, J. W., Mattila, A. S., \& Xiao, Q. (2006). Hotel guest satisfaction and brand performance: The effect of franchising strategy. Journal of Quality Assurance in Hospitality \& Tourism, 7(3), 25-39.

Parasuraman, A., Zeithaml, V. A., \& Berry, L. L. (1985). A conceptual model of service quality and its implications for future research. Journal of Marketing, 49, 41-50.

Phillips, P. A. (1996). Strategic planning and business performance in the quoted UK hotel sector: results of an exploratory study. International Journal of Hospitality Management, 15(4), 347-362.

Phillips, P. A. (1999). Performance measurement systems and hotels: a new conceptual framework. International Journal of Hospitality Management, 18(2), 171-182. 
Phillips, P. A., \& Moutinho, L. (2014). Critical review of strategic planning research in hospitality and tourism. Annals of Tourism Research, 48, 96-120.

Phillips, P., Moutinho, L., \& Godinho, P. (2018). Developing and testing a method to measure academic societal impact. Higher Education Quarterly, 72(2), 121-140.

Phillips, P., Zigan, K., Silva, M. M., \& Schegg, R. (2015). The interactive effects of online reviews on the determinants of Swiss hotel performance: A neural network analysis. Tourism Management, 50, 130-141.

Pizam, A. (2014). Peer-to-peer travel: Blessing or blight? International Journal of Hospitality Management, 38, 118-119.

Pnevmatikoudi, K., \& Stavrinoudis, T. (2016). Classification of hotel performance measurement indicators presented in international scientific research. European Journal of Tourism Research, 12, 82-98.

Punjaisri, K., Wilson, A., \& Evanschitzky, H. (2009). Internal branding to influence employees' brand promise delivery: a case study in Thailand. Journal of Service Management, 20(5), 561-579.

Racherla, P., \& Hu, C. (2010). A social network perspective of tourism research collaborations. Annals of Tourism Research, 37(4), 1012-1034.

Ramachandran, Y., Jordan, P. J., Troth, A. C., \& Lawrence, S. A. (2011). Emotional intelligence, emotional labour and organisational citizenship behaviour in service environments. International Journal of Work Organisation and Emotion, 4(2), 136-157.

Rousseau, D. M. (2004). Psychological contracts in the workplace: Understanding the ties that motivate. The Academy of Management Executive, 18(1), 120-127.

Sainaghi, R. (2006). From Contents to Processes: Versus a Dynamic Destination Management Model (DDMM). Tourism Management, 27(5), 1053-1063.

Sainaghi, R. (2010a). Hotel performance: state of the art. International Journal of Contemporary Hospitality Management, 22(7), 920-952.

Sainaghi, R. (2010b). A meta-analysis of hotel performance, Continental or worldwide style? Tourism Review, 65(3), 46-69.

Sainaghi, R. (2011). RevPAR determinants of individual hotels: evidences from Milan. International Journal of Contemporary Hospitality Management, 23(3), 297-311.

Sainaghi, R., \& Baggio, R. (2014). Structural social capital and hotel performance: Is there a link? International Journal of Hospitality Management, 37(2), 99-110.

Sainaghi, R., \& Baggio, R. (2017). Complexity traits and dynamics of tourism destinations. Tourism Management, 63, 368-382.

Sainaghi, R., \& De Carlo, M. (2016). How to Create Destination Capabilities in the Field of New Product Development. In H. Pechlaner, \& E. Innerhofer, Competence-Based Innovation in Hospitality and Tourism (p. 185-196). Routledge.

Sainaghi, R., \& Mauri, A. (2018). The Milan World Expo 2015: hospitality operating performance and seasonality effects. International Journal of Hospitality Management, $72,32-46$.

Sainaghi, R., Baggio, R., Phillips, P., \& Mauri, A. (2018b). Hotel Performance and Research Streams: A Network Cluster Analysis. International Journal of Contempoary Hospitality Management, 30(8), In press.

Sainaghi, R., Mauri, A., \& d'Angella, F. (2018). Decomposing seasonality in an urban destination: the case of Milan. Current Issues in Tourism, In press, 1-6.

Sainaghi, R., Mauri, A., Ivanov, S., \& D’Angella, F. (2018). Mega events and seasonality: The case of the Milan World Expo 2015. International Journal of Contemporary Hospitality Management, In press. 
Sainaghi, R., Phillips, P., \& Corti, V. (2013). Measuring hotel performance: Using a balanced scorecard perspectives' approach. International Journal of Hospitality Management, $34(1), 150-159$.

Sainaghi, R., Phillips, P., \& d'Angella, F. (2018). The balanced scorecard of a new destination product: Implications for lodging and skiing firms. International Journal of Hospitality Management, In press.

Sainaghi, R., Phillips, P., \& Zavarrone, E. (2017). Performance measurement in tourism firms: A content analytical meta-approach. Tourism Management, 59, 36-56.

Sainaghi, R., Phillips, P., Baggio, R., \& Mauri, A. (2018a). Cross-citation and authorship analysis of hotel performance studies. International Journal of Hospitality Management, 73, 75-84.

Salehzadeh, R., Pool, J. K., Lashaki, J. K., Dolati, H., \& Jamkhaneh, H. B. (2015). Studying the effect of spiritual leadership on organizational performance: an empirical study in hotel industry. International Journal of Culture, Tourism and Hospitality Research, 9(3), 346-359.

Schaufeli, W. B., Salanova, M., González-Romá, V., \& Bakker, A. B. (2002). The measurement of engagement and burnout: A two sample confirmatory factor analytic approach. Journal of Happiness studies, 3(1), 71-92.

Serrat, J. M. (2011). Quality of hotel service and consumer protection: A European contract law approach. Tourism Management, 32(2), 277-287.

Sourouklis, C., \& Tsagdis, D. (2013). Workforce diversity and hotel performance: A systematic review and synthesis of the international empirical evidence. International Journal of Hospitality Management, 34, 394-403.

Starkey, K., \& Madan, P. (2001). Bridging the relevance gap: Aligning stakeholders in the future of management research. British Journal of management, 12(SI), S1-S26.

STR. (2018, April 12). http://www.hotelnewsnow.com/Articles/283839/Hoteliers-shareinsights-on-the-industrys-future.

Tsai, H., Cheung, C., \& Lo, A. (2010). An exploratory study of the relationship between customer-based casino brand equity and firm performance. International journal of hospitality management, 29(4), 754-757.

Tsai, H., Pan, S., \& Lee, J. (2011). Recent research in hospitality financial management. International Journal of Contemporary Hospitality Management, 23(7), 941-971.

Tsai, M. C., \& Lin, C. L. (2014). Bridge the Gaps: From Deficiency to Superior Service. Asia Pacific Journal of Tourism Research, 19(4), 389-415.

Tsang, N., \& Hsu, C. (2011). Thirty years of research on tourism and hospitality management in China: a review and analysis of journal publications. International Journal of Hospitality Management, 30(4), 886-896.

van der Zee, E., \& Vanneste, D. (2015). Tourism networks unravelled; a review of the literature on networks in tourism management studies. Tourism Management Perspectives, 15, 46-56.

Wang, F., Qiu, J., \& Yu, H. (2012). Research on the cross-citation relationship of core authors in scientometrics. Scientometrics, 91(3), 1011-1033.

Wei, X., Qu, H., \& Ma, E. (2012). Decisive mechanism of organizational citizenship behavior in the hotel industry-an application of economic game theory. International Journal of Hospitality Management, 31(4), 1244-1253.

Wernerfelt, B. (1984). A resource-based view of the firm. Strategic Management Journal, 5(2), 171-180.

Wu, C. M., \& Chen, T. J. (2015). Psychological contract fulfillment in the hotel workplace: Empowering leadership, knowledge exchange, and service performance. International Journal of Hospitality Management, 48, 27-38. 
Xiao, H., \& Smith, S. L. (2008). Knowledge impact an appraisal of tourism scholarship. Annals of Tourism Research, 35(1), 62-83.

Xiao, Q., O'Neill, J. W., \& Mattila, A. S. (2012). The role of hotel owners: the influence of corporate strategies on hotel performance. International Journal of Contemporary Hospitality Management, 24(1), 122-139.

Xu, B. J., \& Chan, A. (2010). A conceptual framework of hotel experience and customer-based brand equity: Some research questions and implications. International Journal of Contemporary Hospitality Management, 22(2), 174-193.

Ye, Q., Li, T., \& Law, R. (2013). A coauthorship network analysis of tourism and hospitality research collaboration. Journal of Hospitality \& Tourism Research, 37(1), 51-76.

Yuan, Y. Y., Tseng, Y. H., \& Chang, C. Y. (2014). Tourism subfield identification via journal clustering. Annals of Tourism Research, 47, 77-80.

Yuan, Y., Gretzel, U., \& Tseng, Y. H. (2015). Revealing the nature of contemporary tourism research: Extracting common subject areas through bibliographic coupling. International Journal of Tourism Research, 17(5), 417-431.

Zeglat, D., \& Zigan, K. (2013). Intellectual capital and its impact on business performance: Evidences from the Jordanian hotel industry. Tourism and Hospitality Research, 13(2), 83-100.

Zhao, X., Mattila, A. S., \& Ngan, N. N. (2014). The impact of frontline employees' workfamily conflict on customer satisfaction: The mediating role of exhaustion and emotional displays. Cornell Hospitality Quarterly, 55(4), 422-432. 